\title{
Functionality evaluation of co-processed excipients as diluents in tablets manufactured by wet granulation
}

\author{
Eshovo Apeji Y. ${ }^{1, \bigotimes, ~ M u h a m m a d ~ I Y . ~}{ }^{1}$, Kehinde Olowosulu A. ${ }^{1}$, \\ Owoicho Okpanachi G. ${ }^{2}$, Rukayat Oyi A. ${ }^{1}$
}
${ }^{1}$ Department of Pharmaceutics and Industrial Pharmacy,
Faculty of Pharmaceutical Sciences, Ahmadu Bello University, Zaria
${ }^{2}$ Department of Pharmaceutics and Pharmaceutical
Technology, Faculty of Pharmaceutical Sciences, Gombe
State University, Gombe, Nigeria

Received 29 July, 2020, accepted 8 January, 2020

Abstract Diluents are essential components of a tablet formulation. The type of diluent used in a formulation influences the quality of tablets produced from that formulation. The aim of this study was to evaluate the tableting properties of co-processed excipients (C-PEs) incorporated as diluents in tablet formulation by wet granulation. Metronidazole tablets were prepared by wet granulation incorporating different diluents that were either single component excipients (SCEs) (lactose and microcrystalline cellulose) or C-PEs (Ludipress ${ }^{\oplus}$, StarLac ${ }^{\oplus}$, Prosolv ${ }^{\circledast}$ and AVICEL $\left.{ }^{\oplus} \mathrm{HFE}\right)$. The granules obtained for each formulation were evaluated for particle size analysis, flow properties and compression properties. Tablets weighing $500 \mathrm{mg}$ were compressed from the metronidazole granules on a Single Station Tablet Press using a $12 \mathrm{~mm}$ punch and die tooling system. The tablets were kept for $24 \mathrm{~h}$ post-production, and the properties of weight uniformity, thickness, tensile strength, friability, disintegration time and dissolution profile evaluated subsequently. Results of granule properties showed that variations in parameters evaluated was as a result of differences in the type and composition of diluent used in formulation. Compactibility and tabletability profile of metronidazole granules revealed a better performance with granules processed with C-PE based diluents compared to SCEbased diluents. Tablets formulated with C-PEs as diluents were uniform in tablet weight, disintegrated faster and yielded a faster drug release compared to tablet formulations containing SCEs as diluent. This study reveals the performance advantage of C-PEs as diluents in tablets manufactured by wet granulation and highlights the importance of rational selection of excipients during tablet formulation.

Keywords Diluents-co-processed excipients - tablets - wet granulation

\section{INTRODUCTION}

Tablets constitute about $80-90 \%$ of dosage forms commonly prescribed by medical practitioners for therapeutic management of disease conditions. It is a solid dosage form that exercises advantages over other dosage forms because of its ease of administration, stability profile and amenable to large-scale production. Tablet making involves the addition of a category of substances known traditionally as excipients. Though commonly referred to as the inactive components of a tablet formulation, they are functional in nature because they contribute significantly to the processing, stability, manufacturability and performance of tablets as a dosage form. Depending on the functionality, excipients may be classified as diluents, disintegrants, binders, lubricants, glidants, etc. They are usually added in stated amounts to facilitate the development of a robust tablet product.

Most tablet formulations are prepared by wet granulation and require the addition of all the listed excipients. One critical excipient that is incorporated in tablet formulations by wet granulation is the diluent. Diluents also known as fillers or bulking agents are routinely added in formulation development to increase the bulk of the formulation and to bind other excipients with the active pharmaceutical ingredient (API). The use of diluents becomes more significant in tablet formulations of low-dose API where the diluent occupies a larger proportion of the formulation. Hence, the properties of diluents become extremely important and can significantly influence the final product property. Studies have been carried out to characterise the mechanical properties of widely used pharmaceutical diluent powders to understand how their mechanical properties impact on the manufacturing performance and properties of the final product (Zhang et al., 2017). These diluent powders are more 
or less single component excipients (SCEs) like lactose, starch, mannitol, microcrystalline cellulose (MCC), which have been used in tablet formulation by wet granulation. However, due to the limited functionality of SCEs in tablet formulation, attention has shifted to the development of novel excipients with improved functionality.

Co-processing as a particle engineering technique has been used to develop novel excipients with improved functionality. This technique involves the combination of two or more excipients in optimal proportions at the subparticle level using a defined method that promotes synergy of properties in composite particles while minimising the limitations of the constituent excipient in the final product. Some of the functionality improvement recorded with coprocessed excipients (C-PEs) includes enhanced flowability, compressibility, dilution potential and low lubricant sensitivity and/or moisture sensitivity (Nachaegari and Bansal, 2004). Many of these C-PEs have been designed originally as fillerbinders in direct compression formulation (Wang et al., 2015), as superdisintegrating agents for orodispersible tablets (Daraghmeh et al., 2015) and as drug-release retardants in controlled release formulations (Choudhari et al., 2018). No study has reported the use of C-PEs as diluents in wet granulated tablet formulations.

Considering the improved tableting profile of C-PEs, changing the diluent type in a wet granulated tablet formulation from an SCE to a C-PE is likely to result in better tableting properties of the drug product. Hence, the aim of this study is to evaluate the tableting properties of C-PEs as diluents in a wet granulated formulation of metronidazole tablets. Two samples each of lactose-based C-PEs (Ludipress, StarLac') and MCC-based C-PEs (Prosolv", AVICEL ${ }^{\circ} \mathrm{HFE}$ ) were evaluated as diluents in comparison to their SCEs (lactose, MCC).

\section{MATERIALS AND METHODS}

\section{Materials}

Metronidazole ( $\mathrm{CDH}$ laboratory Chemicals, India), lactose (DFE Pharma, Germany), maize starch (Burgoyne Burbidge \& Co. India, Mumbai), Acacia (Kerry Ingredients and flavours Ltd, Ireland), StarLac ${ }^{\circledast}$ (Roquette Pharma, France), Ludipress ${ }^{\circledR}$ (BASF SE, Germany), MCC, Prosolv ${ }^{\circ}$, sodium stearyl fumarate (JRS Pharma, Germany), Avicel'HFE-102 (FMC BioPolymer AS, Norway), colloidal silicon dioxide (Evonik Industries, Germany), distilled water.

\section{Preparation of Metronidazole Granules}

Metronidazole granules were prepared by wet granulation according to the formulation given in Table 1. A powder blend of metronidazole $(20 \mathrm{~g})$, lactose $(19.5 \mathrm{~g})$ and maize starch $(5 \mathrm{~g})$ was obtained by low shear mixing in a mortar with a pestle (Abdallah et al., 2014). Binder solution was prepared containing acacia $(10 \% \mathrm{w} / \mathrm{w})$ and incorporated to mass the powder mix. The wet powder mass obtained was screened through a $1.6 \mathrm{~mm}$ sieve to generate granules. The granules formed were allowed to dry for $20 \mathrm{~min}$ in the oven, screened through a $1 \mathrm{~mm}$ sieve and then drying completed in the hotair oven (Gallenkamp BS, England) at $40^{\circ} \mathrm{C}$ for $2 \mathrm{~h}$.

\section{Characterisation of Metronidazole Granules}

\section{Moisture Content}

Residual moisture content of each granule formulation was determined using the gravimetric method (Olayemi et al., 2008). A sample of granules $(1 \mathrm{~g})$ for each formulation was dried to constant weight in an oven at $105^{\circ} \mathrm{C}$ for a period of $1 \mathrm{~h}$. The percentage moisture content was calculated using Eq. 1:

$\%$ moisture content $=\frac{\text { initial weight }- \text { final weight }}{\text { inial weight }} \times 100 \%$

\section{Particle Size Analysis}

Particle size analysis was carried out using the sieving method as described by Ohwoavworhua and Adelakun (2010). Test sieves ranging from $500 \mu \mathrm{m}$ to $75 \mu \mathrm{m}$ aperture size were arranged in a descending order. A sample of granules $(20 \mathrm{~g})$ was placed in the top sieve, and the setup shaken for $10 \mathrm{~min}$ at an amplitude of $1 \mathrm{~mm}$. The weight of granules retained on each sieve was determined and a plot of cumulative weight (undersize) against sieve size was drawn to extrapolate the median particle diameter $\left(\mathrm{d}_{50}\right)$.

\section{True Density}

True density for each granule formulation was determined using the liquid displacement method (Olayemi et al., 2008). The empty weight of a pycnometer bottle was obtained, filled with xylene, and its weight determined. A sample of the granules ( $2 \mathrm{~g}$ ) was transferred into the bottle and the excess liquid wiped off. The new weight was determined, and Eq. 2 was used to compute true density having obtained the weight of xylene displaced by the sample:

$\rho_{T}=\frac{\text { weight of sample } \times \rho \text { of } x y l e n e(0.864)}{\text { weight of } x y l e n e \text { displaced by sample }}$

\section{Angle of Repose}

Angle of repose for each granule formulation was measured using the method described by Pilpel (1965). The angle of repose was calculated using Eq. 4, and a mean of three replicates was reported:

$\operatorname{Tan} \theta=\frac{h}{r}$

where $h$ is the height of the cone and $r$ is the radius of the cone base. 
Table 1. Formula for preparing metronidazole granules and tablets ( $n=100$ tablets).

\begin{tabular}{|c|c|c|c|c|c|c|}
\hline \multirow[b]{2}{*}{ Ingredients } & \multicolumn{6}{|c|}{ Formulations } \\
\hline & $\mathbf{I}$ & II & III & IV & $\mathbf{V}$ & VI \\
\hline $\begin{array}{l}\text { Metronidazole } \\
(40 \%)\end{array}$ & 20.00 & 20.00 & 20.00 & 20.00 & 20.00 & 20.00 \\
\hline Diluent (39\%) & 19.50 & 19.50 & 19.50 & 19.50 & 19.50 & 19.50 \\
\hline Maize starch (10\%) & 5.00 & 5.00 & 5.00 & 5.00 & 5.00 & 5.00 \\
\hline Acacia (10\%) & 5.00 & 5.00 & 5.00 & 5.00 & 5.00 & 5.00 \\
\hline CSD $(0.5 \%)$ & 0.25 & 0.25 & 0.25 & 0.25 & 0.25 & 0.25 \\
\hline SSF $(0.5 \%)$ & 0.25 & 0.25 & 0.25 & 0.25 & 0.25 & 0.25 \\
\hline Total (g) & 50.00 & 50.00 & 50.00 & 50.00 & 50.00 & 50.00 \\
\hline
\end{tabular}

Diluents (I - lactose, II - Ludipress ${ }^{\circledR}$, III - StarLac ${ }^{\oplus}, I V-M C C, V$ - Prosolv ${ }^{\circledR}$, VI - AVICEL ${ }^{\oplus H F E), ~ C S D ~-~ c o l l o i d a l ~ s i l i c o n ~ d i o x i d e, ~ S S F ~-~}$ sodium stearyl fumarate

\section{Bulk and Tapped Densities}

Bulk density (BD) and tapped density (TD) were calculated using Eqs. 4 and 5, respectively, according to the method described by USP (2012). The values obtained for BD and TD were used to compute Carr's index $(\mathrm{Cl})$ and Hausner's ratio (HR) using Eqs. 6 and 7, respectively:

$$
\begin{aligned}
& \mathrm{BD}=\frac{\text { weight of granules }}{\text { Bulk volume }} \\
& \mathrm{TD}=\frac{\text { weight of granules }}{\text { Tapped volume }} \\
& \mathrm{Cl}=\frac{\mathrm{TD}-\mathrm{BD}}{\mathrm{TD}} \times 100 \\
& \mathrm{HR}=\frac{T D}{B D}
\end{aligned}
$$

\section{Compaction Studies}

Compacts weighing $500 \mathrm{mg}$ were compressed at pressures ranging from $40 \mathrm{MPa}$ to $250 \mathrm{MPa}$ on a Hydraulic Carver Press. The compacts were kept for $24 \mathrm{~h}$ after compression to allow for elastic recovery. The weight, thickness and crushing strength of each compact was measured, and the parameters of tensile strength and porosity were computed for each compact. Plots of porosity against compression pressure (compressibility), tensile strength against porosity (compactibility) and tensile strength against compression pressure (tabletability) were generated for each granule formulation. The plots were generated with mean values without including standard deviation.

\section{Tableting}

Metronidazole tablets were prepared by compressing the granules lubricated with corresponding quantities of CSD and SSF (Table 1) on a Single Station Tablet Press (Type EKO, Erweka, Germany) using $12 \mathrm{~mm}$ flat-faced punches at 10 $\mathrm{kN}$. Tablets weighing $\sim 500 \mathrm{mg}$ were obtained and kept for
$24 \mathrm{~h}$ to allow for elastic recovery before evaluation of tablet properties.

\section{Evaluation of Tablet Properties}

Tablet properties for each formulation were evaluated according to BP requirements (2013). The weight of 20 tablets selected at random from each formulation were obtained, and the mean and standard deviations were calculated to ascertain uniformity in weight of tablets for each formulation. The thickness and crushing strength of 10 randomly sampled tablets from each formulation were measured using the Digital Vernier Calliper and Monsanto Hardness Tester, respectively. The mean and standard deviation for each parameter were recorded. The corresponding tensile strength (TS) was calculated for each formulation using the following equation (Fell and Newton, 1970):

$T s=\frac{2 F}{\pi d t}$

where $F$ is the crushing strength, $d$ and $t$ are the diameter and thickness, respectively.

Ten tablets from each formulation were randomly selected, accurately weighed, placed in the chamber of Digital Friability Test Apparatus 903 (Environmental and Scientific Instruments CO., India) and allowed to rotate at $25 \mathrm{rpm}$ for $4 \mathrm{~min}$. Tablets were removed from the chamber, gently cleaned from dust particles and accurately weighed. Friability was calculated in terms of percentage weight loss using Eq. 9:

Weight loss $(\%)=\frac{w_{i}-w_{f}}{w_{i}} \times 100 \%$

where $w_{i}$ and $w_{f}$ are the weights of the tablets before and after friability test, respectively.

The time taken for six tablets from each formulation to disintegrate was determined using the BJ-3 Disintegration 


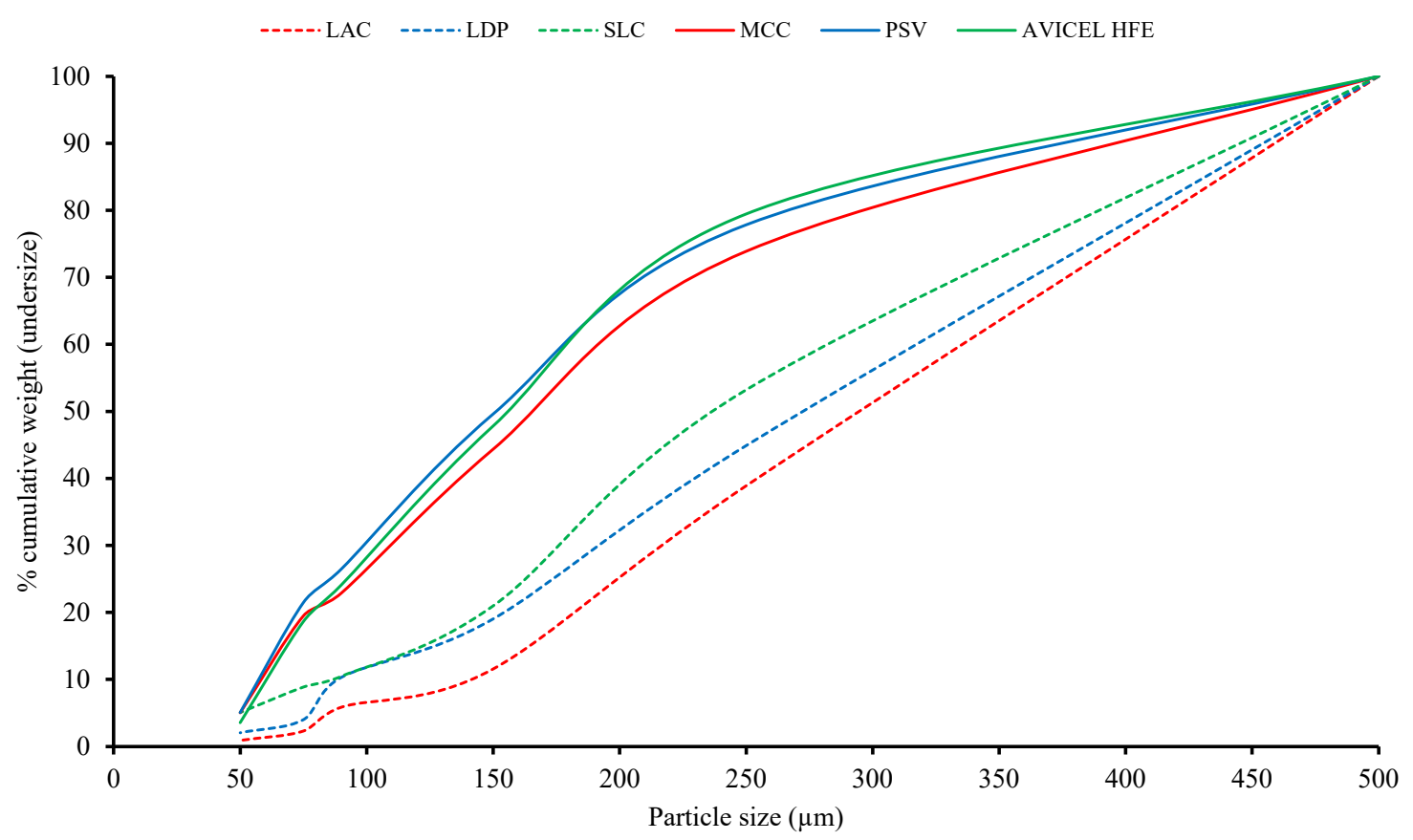

Figure 1. Particle size distribution of LAC (I), LDP (II), SLC (III), MCC (IV), PSV (V), \& AVICELÂ ${ }^{\oplus H F E ~(V I) . ~}$

Tester (Ningbo Hinotek Instrument Co., Ltd, China). The experiment was conducted in a controlled temperature environment of $37 \pm 0.5^{\circ} \mathrm{C}$ using distilled water as the medium for disintegration. The mean and standard deviation of six replicates were computed and recorded for each formulation. In vitro dissolution studies were conducted according to USP specifications (USP, 2011) using the Tablet Dissolution Test Apparatus (Model 912, Electronics India, Kamli - 173220, Parwanoo, Himachal Pradesh, India). One tablet was placed in a basket submerged in a dissolution chamber containing 900 $\mathrm{mL}$ of $0.1 \mathrm{~N} \mathrm{HCl}$ maintained at $37^{\circ} \mathrm{C}$. The basket was allowed to rotate at $100 \mathrm{rpm}$, and $5 \mathrm{~mL}$ samples were withdrawn after 5, 10, 15, 20, 30, 45 and $60 \mathrm{~min}$ of drug release. The dissolution medium was replaced with equal volume of 0.1 $\mathrm{N} \mathrm{HCl}$ after each withdrawal. The samples collected were filtered and sufficiently diluted with $0.1 \mathrm{~N} \mathrm{HCl}$ before taking the absorbance readings at $277 \mathrm{~nm}$ using the ultraviolet (UV) spectrophotometer (UV-1800 Spectrophotometer, Shimadzu Corporation, USA). The amount of drug released (\%) was calculated based on the equation, $y=0.0395 x+0.1314, r^{2}=$ 0.999 , derived from the calibration curve of metronidazole and a plot of drug released (\%) against time was generated for the six tablet formulations. The plot was generated with mean values without including standard deviation.

\section{RESULTS AND DISCUSSION}

Tablet production by wet granulation involves the addition of a diluent at the formulation stage. The goal of this study was to evaluate the performance of C-PE as diluents in tablets manufactured by wet granulation in comparison to SCE.

Physical properties of granules prepared using the different diluents consisting of C-PE and SCE materials are summarised in Table 2. Particle size $\left(d_{50}\right)$ of granules ranged from $150 \mu \mathrm{m}$ to $290 \mu \mathrm{m}$ as extrapolated from the particle size distribution curve (Fig. 1). Lactose-based formulations (I-III) possessed larger particle sizes relative to MCC-based formulations. This may be attributed to the low agglomerating effect of MCC-based excipients when used in wet granulation. It was generally observed that the formulations containing C-PEs as diluents (II, III, V, VI) had lower particle size compared to formulations containing SCEs as diluents (I and IV). This may be linked to the primary particle sizes of C-PEs, which are relatively smaller having been produced by spray drying (Dong et al., 2018).

Angle of repose values for all granule formulations did not exceed $30^{\circ}$, implying that the granules possessed good flow properties (Osei-Yeboah et al., 2014). Generally, tablet formulations prepared by wet granulation are expected to flow well as a result of the agglomeration occurring during granulation leading to particle size enlargement that enhances flow. This is a quality attribute that granules must possess to ensure uniformity in content and weight of tablets during production (Osamura et al., 2018). BD and TD ranged from 0.41 to $0.55 \mathrm{~g} / \mathrm{cm}^{3}$ and 0.56 to $0.67 \mathrm{~g} / \mathrm{cm}^{3}$, respectively, with lactose-based formulations recording higher values for both parameters. This may not be unrelated to the fluffy and fibrous nature of MCC that results in a higher bulk volume when 
Table 2. Physical properties of metronidazole granules prepared with different diluents.

\begin{tabular}{|c|c|c|c|c|c|c|}
\hline & \multicolumn{7}{|c|}{ Formulations with diluents } \\
\hline Parameters & I & II & III & IV & V & VI \\
\hline Particle size $\left(\mathrm{d}_{50^{\prime}} \mu \mathrm{m}\right)$ & 290.00 & 270.00 & 235.00 & 165.00 & 150.00 & 155.00 \\
\hline Angle of repose $\left(^{\circ}\right)$ & $30.03 \pm 0.20$ & $29.63 \pm 0.50$ & $28.58 \pm 1.87$ & $30.25 \pm 0.61$ & $27.52 \pm 0.32$ & $28.27 \pm 0.56$ \\
\hline Bulk density $\left(\mathrm{g} / \mathrm{cm}^{3}\right)$ & $0.55 \pm 0.01$ & $0.54 \pm 0.02$ & $0.48 \pm 0.01$ & $0.43 \pm 0.03$ & $0.43 \pm 0.03$ & $0.41 \pm 0.01$ \\
\hline Tapped density $\left(\mathrm{g} / \mathrm{cm}^{3}\right)$ & $0.66 \pm 0.02$ & $0.67 \pm 0.00$ & $0.60 \pm 0.01$ & $0.62 \pm 0.07$ & $0.58 \pm 0.01$ & $0.56 \pm 0.02$ \\
\hline True density $\left(\mathrm{g} / \mathrm{cm}^{3}\right)$ & 1.46 & 1.44 & 1.54 & 1.52 & 1.52 & 1.54 \\
\hline Carr's Index $(\%)$ & $16.44 \pm 0.32$ & $18.86 \pm 3.10$ & $19.28 \pm 0.33$ & $30.95 \pm 3.37$ & $26.51 \pm 2.92$ & $25.79 \pm 1.83$ \\
\hline Hausner's ratio & $1.20 \pm 0.00$ & $1.23 \pm 0.05$ & $1.24 \pm 0.01$ & $1.45 \pm 0.07$ & $1.36 \pm 0.05$ & $1.35 \pm 0.03$ \\
\hline Moisture content $(\%)$ & 5.00 & 5.00 & 5.00 & 7.00 & 9.00 & 8.00 \\
\hline
\end{tabular}

I- lactose, II - Ludipress', III -StarLac', IV - MCC, V-Prosolv', VI - AVICEL ${ }^{\circ}$ HFE

loosely packed resulting in low $\mathrm{BD}$ and TD (Chaerunisaa et al., 2019). With respect to $\mathrm{Cl}$ and HR, MCC-based formulations (IV-VI) were found to be more compressible. Higher values of $\mathrm{Cl}$ and HR imply better compressibility, while lower values of the same indices correspond to better flowability. The lower particle size of MCC-based formulations tends to promote a greater degree of packing during consolidation of the granules because of significant reduction in powder porosity and lower volume occupied by the granules, which translates to high values of $\mathrm{Cl}$ and $\mathrm{HR}$.

True density values did not vary significantly across the different granule formulations, though it was observed that granulations formulated with lactose-based diluents (I-III) had relatively lower values in comparison to MCC-based formulations. True density is a measure of intermolecular distance between bonding surfaces and becomes critical in estimating the compaction behaviour of the material. Materials having higher true density correspond to a greater propensity for plastic deformation during compression, leading to tablets of higher tensile strength (Sun, 2011). Moisture content of granules ranged from $5 \%$ to $9 \%$, with MCC-based granules having higher values relative to those of lactose-based granules. Slight differences in moisture content may be ascribed to the hygroscopicity of MCC (Sun, 2016). Generally, it was observed that there were variations in granule properties as a result of the type of diluent used in the formulation. In addition, the properties of the granules were also influenced by whether the diluent was either an SCE or C-PE material.

The compressibility-tabletability-compactibility (CTC) profile of the various granule formulation is illustrated in Figs. 2-4. The compressibility plot (Fig. 2) denotes the effect of compression pressure on the porosity of compacts. For all the granule formulations (I-VI), the porosity of compacts was found to decrease with increasing compaction pressure. Compressibility describes the ability of a material to undergo volume reduction when pressure is applied and is usually indicated by a decrease in volume or porosity and a corresponding increase in relative density or solid fraction (Joiris et al., 1998; Upadhyay et al., 2013). For the lactose-based formulations (Fig. 2a), the extent of reduction in porosity did not appear to differ widely across the three granule formulations (I-III). However, it was observed with MCC-based formulations (Fig. 2b) that the extent of porosity reduction differed across the three granule formulations (IV-VI) with MCC granules having the highest degree of compressibility. At $250 \mathrm{MPa}$, a porosity less than 0.02 was obtained for MCC as compared to 0.04 for AVICEL ${ }^{\circ} \mathrm{HFE}$ and 0.05 for PSV. This may be attributed to the deformation behaviour of MCC, which undergoes extensive plastic deformation during compression, leading to an increased bonding area that promotes compressibility. Hence, in terms of compressibility, MCC, an SCE material had a superior profile compared to C-PE materials. The compressibility of any material is usually determined by many factors like mechanical and particle properties (Sun, 2011).

The compactibility plot displayed as Fig. 3 graphically illustrates the effect of porosity on the tensile strength of compacts. Compactibility refers to the ability of a powder to form coherent compacts under the effect of densification (Sonnergaard, 2006). It describes the relationship between tablet microstructure (porosity) and tensile strength (Sun, 2017; Zeitler \& Rades, 2017) For all granule formulations (I$\mathrm{VI})$, tensile strength of compacts increased with a decrease in porosity. The compactibility profile (Fig. 3a) showed that at a porosity of 0.05 , higher tensile strength values were obtained for formulations containing C-PE as diluents (II and III) when compared to the formulation containing SCE as diluent (I). A similar occurrence was observed with MCCbased formulations (Fig. 3b), as higher tensile strength values were obtained at a porosity of 0.05 for formulations containing C-PEs as diluents (V and VI) compared to the formulation containing SCE as diluent (IV). This implies that the compactibility profile of CPEs as diluents was superior to that of SCE material as diluent. Higher compactibility suggests higher inter-particulate bonding. This has been 

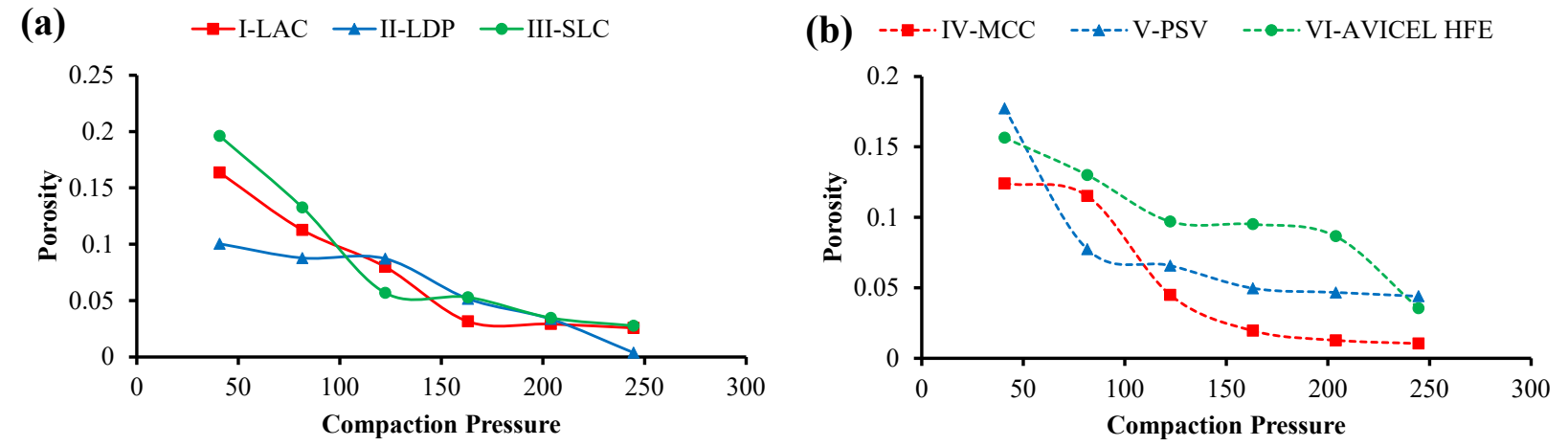

Figure2. Compressibility plot of (a) Lactose-based formulations, (b) MCC-based formulations.
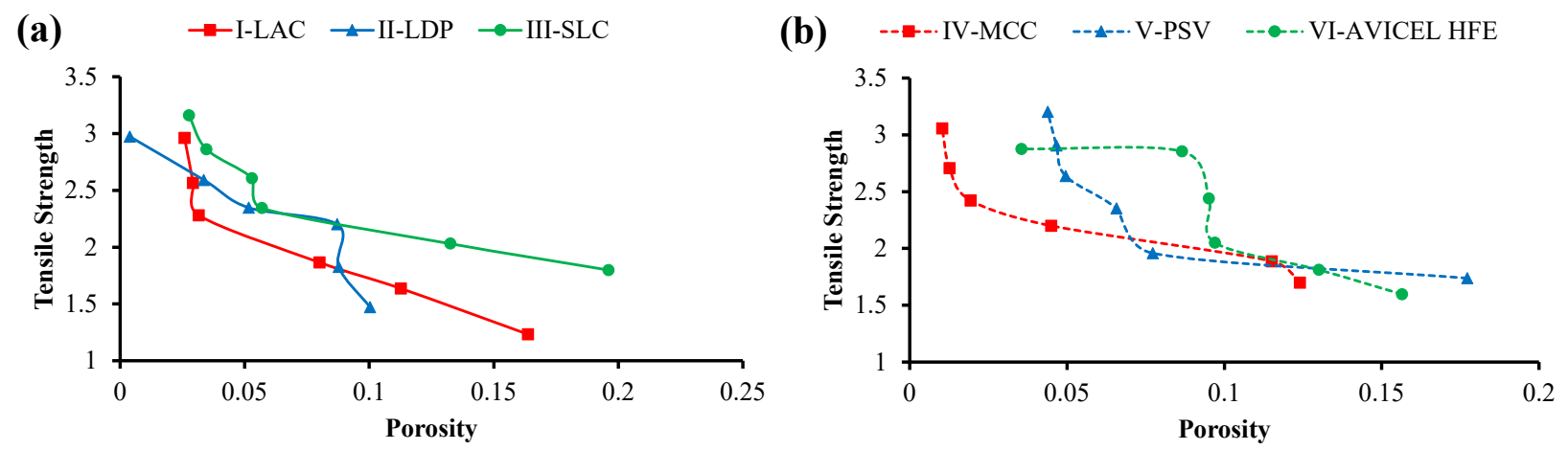

Figure 3. Compactibility plot of (a) Lactose-based formulations, (b) MCC-based formulations.
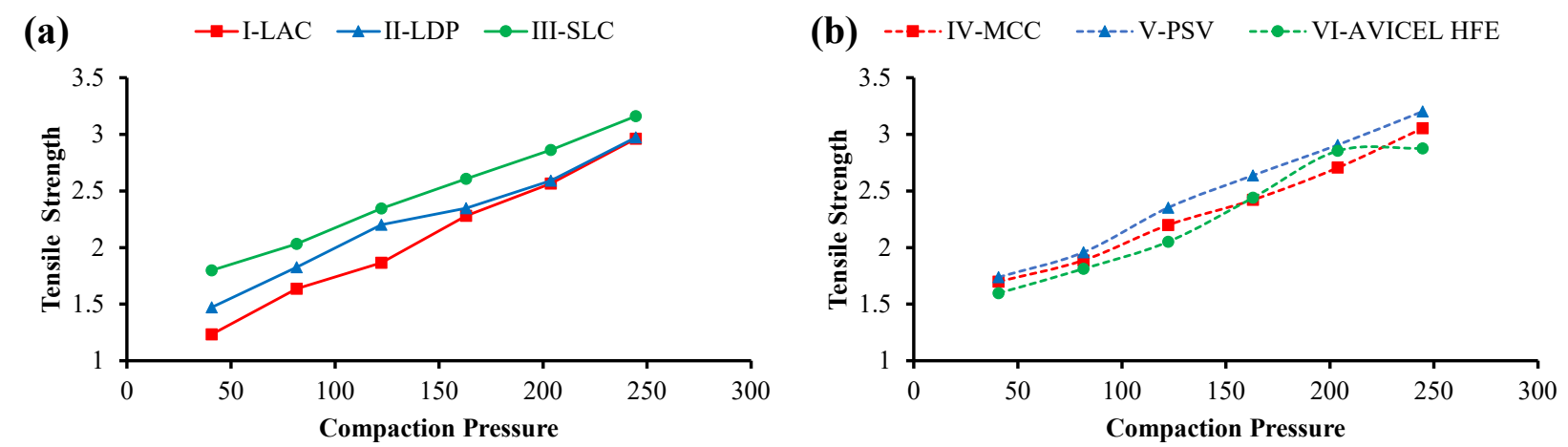

Figure 4. Tabletability plot of (a) Lactose-based formulations, (b) MCC-based formulations.

attributed to an increase in interfacial adhesion occurring during compaction, leading to an increase in bonding strength per unit area giving rise to tablets of higher tensile strength at low porosity. Many composite excipients demonstrate an improvement in compactibility as a result of engineering of particle properties during co-processing. This explains why C-PEs performed better as diluents with respect to compactibility when compared to SCEs.
The tabletability profile of all six granule formulations $(\mathrm{I}-\mathrm{VI})$ is presented as Fig.4. The plot correlates the relationship between compression pressure and tensile strength of compacts. All the granule formulations displayed an increase in tensile strength with increase in compaction pressure. Formulations containing C-PE as diluents (II, III, V and VI) produced tablets with relatively higher tensile strength across the entire range of compaction pressure in comparison to formulations containing SCE as 
Table 3. Physical properties of metronidazole tablets prepared using different diluents.

\begin{tabular}{|c|c|c|c|c|c|c|}
\hline & \multicolumn{7}{|c|}{ Formulations with diluents } \\
\hline Parameters & I & II & III & IV & V & VI \\
\hline Mean weight (mg) & $503.10 \pm 26.62$ & $\begin{array}{c}507.00 \pm \\
11.41\end{array}$ & $\begin{array}{c}501.80 \pm \\
13.40\end{array}$ & $\begin{array}{c}511.90 \pm \\
15.21\end{array}$ & $\begin{array}{c}509.20 \pm \\
12.84\end{array}$ & $506.00 \pm 9.36$ \\
\hline Thickness (mm) & $4.02 \pm 0.13$ & $4.33 \pm 0.06$ & $4.38 \pm 0.02$ & $4.02 \pm 0.05$ & $4.27 \pm 0.06$ & $4.08 \pm 0.02$ \\
\hline $\begin{array}{c}\text { Tensile strength } \\
(\mathrm{MPa})\end{array}$ & $0.78 \pm 0.12$ & $0.67 \pm 0.30$ & $0.57 \pm 0.05$ & $1.19 \pm 0.11$ & $0.77 \pm 0.04$ & $1.20 \pm 0.23$ \\
\hline Friability (\%) & 1.20 & 1.95 & 2.00 & 0.78 & 1.1 & 0.69 \\
\hline $\begin{array}{c}\text { Disintegration time } \\
(\mathrm{min})\end{array}$ & $14.01 \pm 1.57$ & $10.99 \pm 1.39$ & $10.96 \pm 1.08$ & $25.40 \pm 0.34$ & $5.77 \pm 2.37$ & $0.32 \pm 0.06$ \\
\hline $\mathrm{T}_{80 \%}(\mathrm{~min})$ & 18.00 & 15.00 & 14.00 & 30.00 & 4.00 & 35.00 \\
\hline
\end{tabular}

I- lactose, II - Ludipress', III-StarLac', IV-MCC, V-Prosolv', VI-AVICEL ' HFE

diluent (I and IV). This implies that C-PE materials used as diluents provided a greater bonding strength per unit surface area, with minimal elastic recovery during decompression stage of tableting, resulting in tablets with relatively higher tensile strength. Improved tabletability profile of C-PEs has been attributed to the material properties of C-PE that combines a plastic deforming excipient and brittle material into the composite structure of the C-PE, thereby reducing the tendency for significant elastic recovery upon ejection of tablet (Nachaegari \& Bansal, 2004). Substantial elastic recovery occurring after ejection leads to the breakage of bonds formed during tableting, thereby lowering the tensile strength upon relaxation of tablet. This explains why granule formulations consisting of SCE as diluent returned tablets of lower tensile strength under the effect of compaction pressure. Hence, tabletability is described as the capacity of a powdered material to be transformed into a tablet of specified strength (tensile strength) under the effect of compaction pressure (Joiris et al., 1998; Yadav et al., 2017).

The physical properties of metronidazole tablets prepared using the different diluents is summarised in Table 3. Average tablet weight ranged from $503.1 \mathrm{mg}$ to $511.9 \mathrm{mg}$. Formulations containing C-PE as diluents (II, III, V and VI) produced tablets with a uniform distribution in tablet weight compared to formulations containing SCE as diluents (I, IV). This implies that the use of C-PE as diluents improved the flow of granules during tableting, resulting in the formation of tablets of narrow distribution in weight. Thickness of tablets did not differ significantly across the various formulations ranging from 4.02 $\mathrm{mm}$ to $4.33 \mathrm{~mm}$ and could be attributed to the compressibility of the granules that generated the tablets. Tablet hardness was characterised using tensile strength, and values were ranked in the following order, $\mathrm{VI}>\mathrm{IV}>\mathrm{I}>\mathrm{V}>\mathrm{II}>\mathrm{III}$, with formulations containing C-PE as diluents returning lower tensile strength values compared to formulations containing SCE as diluents. The lowering of tensile strength of tablets formulated with C-PE as diluents may be associated with the inability of the diluents to exert their effect as directly compressible excipients in tablets formulated by wet granulation. Formulation studies have shown that directly compressible excipients tend to lose their compressibility when incorporated in tablet formulations by wet granulation (Nguyen et al., 2015). Tablet friability parameter was evaluated to measure the weakness of the tablet. Many manufacturers recommend a limit of $1 \%$ as tablet friability (Adjei et al., 2017). Only two tablet formulations (IV and VI) passed the friability test. The lactose-based formulations (I-III) did not pass the friability test possibly due to the brittle nature of the diluents used in the formulations. It was generally observed that MCC-based formulations passed the friability test possibly due to the mechanical property of the diluents. MCC-based diluents are known to undergo extensive plastic deformation during tableting, resulting in increased bonding surface area and inter-particulate bonding that produces tablets with higher tensile strength (Edge et al., 2000). Tablet friability of all the formulations corresponded to the tensile strength of tablets. Tablets having lower tensile strength gave rise to high friability and vice versa.

According to BP requirements, immediate release tablets are expected to disintegrate within $15 \mathrm{~min}$. All the tablet formulations passed the disintegration test, except for formulation IV containing MCC as diluent, which failed the disintegration test. MCC is commonly used as a directly compressible excipient because of its exceptional binding properties and prolongs disintegration time when used in concentrations exceeding 15\% in tablet formulations (Apeji et al., 2011). It was observed that tablets formulated with C-PE as diluents (II, III, V and VI) disintegrated faster when compared to tablets containing SCE as diluents (I and $\mathrm{VI})$. This has been attributed to the composition of the C-PE, which usually contains an excipient with excellent disintegrant properties like mannitol, starch and crospovidone found in AVICEL'HFE (VI), StarLac (III) and LDP (II), respectively. In addition, the high friability of the tablets must have contributed to rapid disintegration by promoting rapid uptake of water due to high porosity of the tablet created by the relatively high friability.

The rate and extent of drug release from metronidazole tablets was illustrated in Figs. 5 and 6. Drug-release profile 


$$
\rightarrow-I-L A C \rightarrow \text { II-LDP } \rightarrow \text { III-SLC }
$$

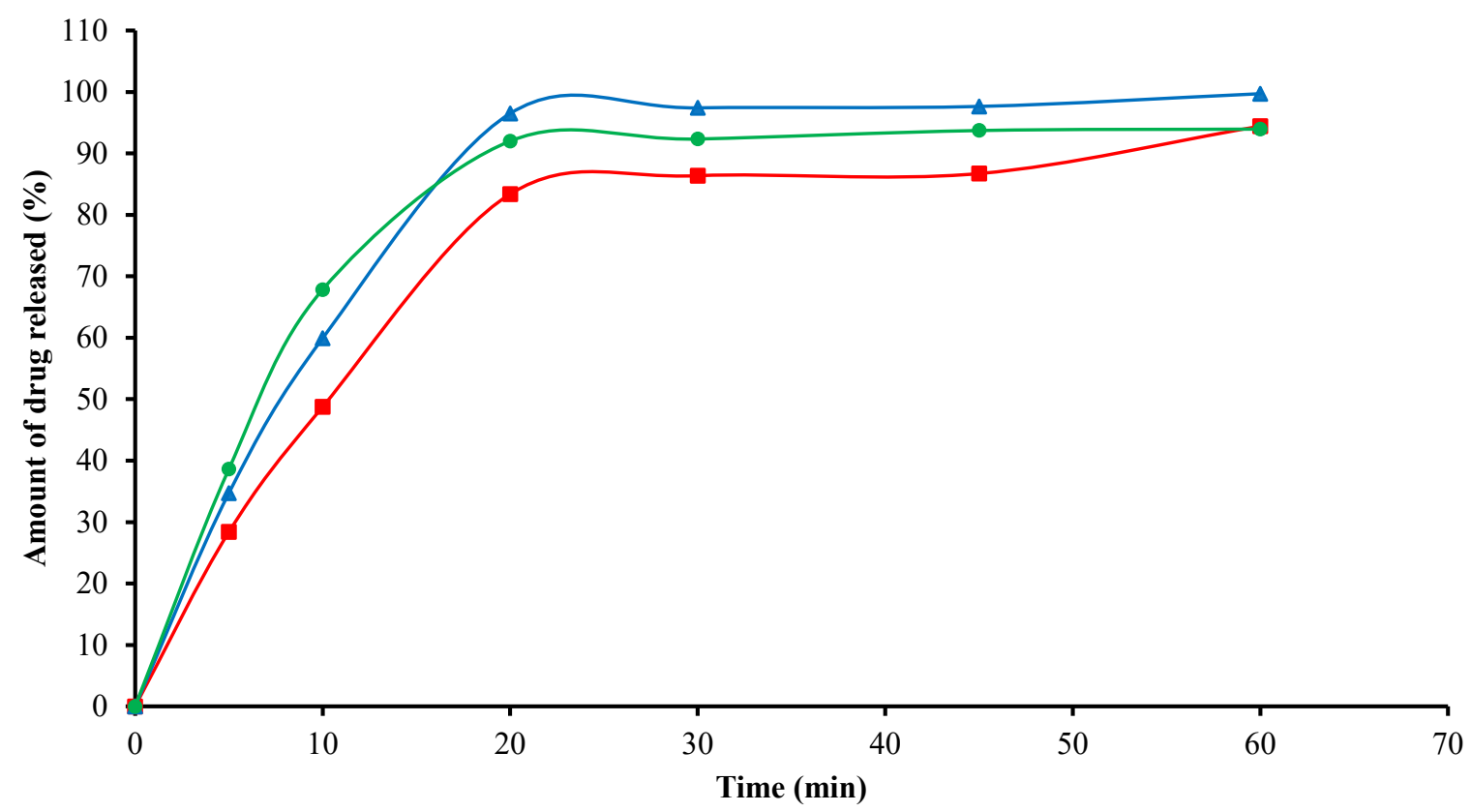

Figure 5. Drug-release profile of Lactose-based formulations.

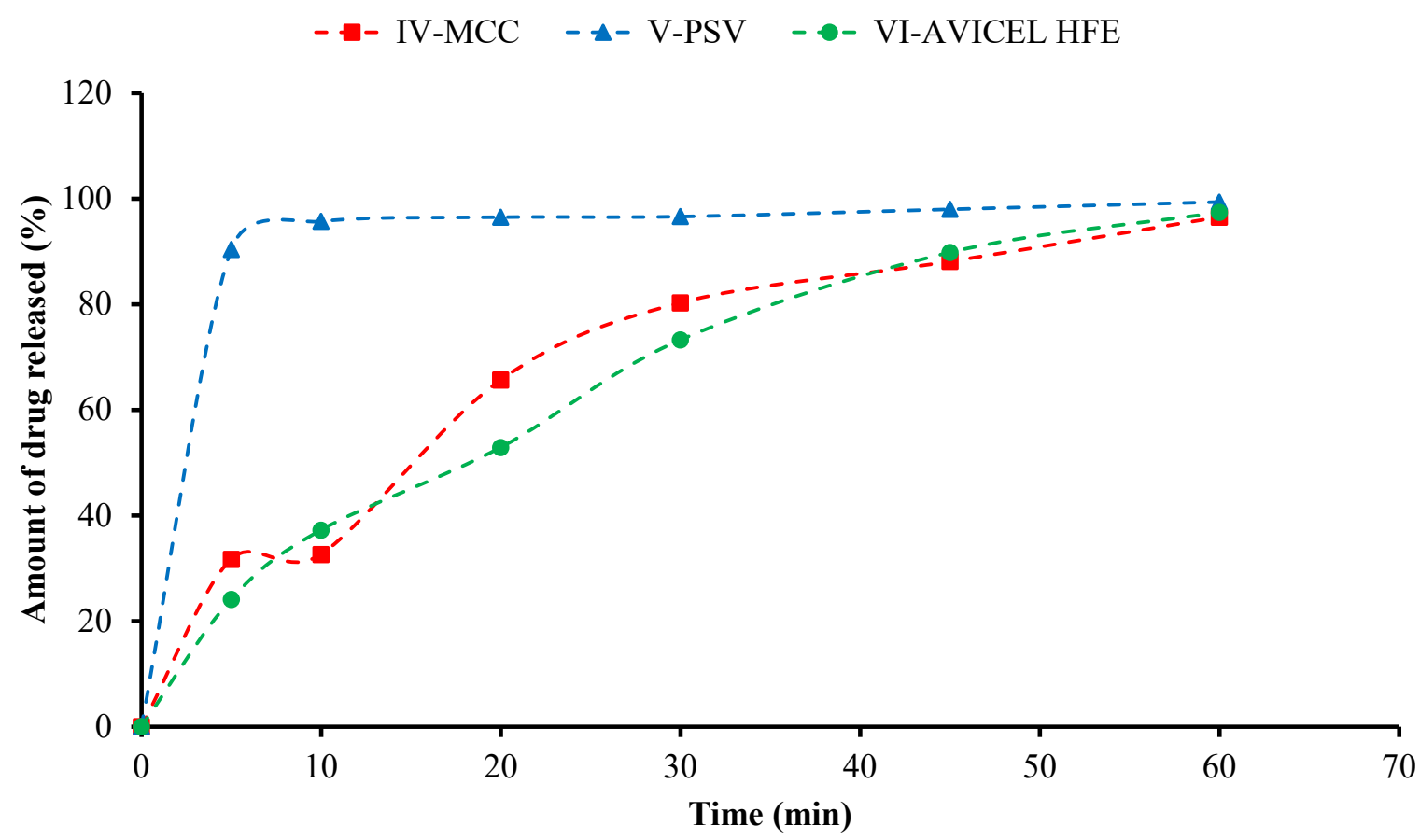

Figure 6. Drug-release profile of MCC-based formulations. 
for lactose-based formulations (Fig. 5) shows that the rate and extent of drug release was faster with tablets formulated with C-PE as diluents (II and III) compared to drug release from tablets containing SCE as diluent (I).

A similar pattern was observed for the MCC-based formulations (Fig. 6) where tablets formulated with C-PE as diluent (V) gave a faster and more extensive drug release. The rate and extent of drug release for all tablet formulations corresponded with the time it took for the tablets to disintegrate, as presented in Table 3. However, it was not so for tablets formulated with AVICEL ${ }^{\circ H F E}$ as diluent as the rapid disintegration time did not correspond to faster drug release possibly because of compact crystal structure of mannitol present in AVICEL ${ }^{\circ} \mathrm{HFE}$, which may have impeded drug solubility (Daraghmeh et al., 2010). Nonetheless, this tablet formulation passed the dissolution test, which was within the USP limits (not less than $85 \%$ of the labelled amount of metronidazole should dissolve in 60 mins). All other formulations prepared with different diluents passed the dissolution test.

\section{CONCLUSION}

The aim of the study was to evaluate the tableting properties of C-PEs used as diluents in tablets formulated by wet granulation in comparison to SCEs. The properties of the granules prepared using various diluents differed on the basis of the type of diluent (lactose-based or MCC-based) and composition of the diluent (C-PE or SCE). With respect to the compaction properties of granules, C-PE-based formulations performed better in terms of compactibility and tabletability when compared to SCE-based formulations. The tableting properties of the various tablet formulations revealed the superiority of C-PE-based formulations in tablet weight uniformity, disintegration and drug-release profile of the corresponding tablet formulation. This study, therefore, summarises the performance advantages of incorporating C-PEs as diluents in tablets manufactured by wet granulation and underscores the necessity for rational selection of excipients during tablet formulation.

\section{References}

[1] Abdallah DB, Charoo NA, Elgorashi AS. Comparative binding and disintegrating property of Echinochloa colona starch (difra starch) against maize, sorghum, and cassava starch. Pharm Biol. 2014; 52:935-943.

[2] Adjei FK, Osei YA, Kuntworbe N, Ofori-kwakye K. Evaluation of the disintegrant properties of native starches of five new cassava varieties in paracetamol tablet formulations. J Pharm. 2017:1-9

[3] Apeji Y, Oyi A., Hassan M. Formulation and evaluation of ascorbic acid tablets by direct compression using microcystalline starch as a direct compression excipient. Int J Heal Res. 2011; 4:113-118

[4] Chaerunisaa AY, Sriwidodo S, Abdassah M. Microcrystalline cellulose as pharmaceutical excipient. In: Pharmaceutical Formulation Design - Recent Practices. IntechOpen, 2019, pp $1-22$

[5] Choudhari PK, Jain HK, Sharma P, Srivastava B. A novel coprocessed directly compressible release-retarding polymer: In vitro, solid state and in vivo evaluation. Futur J Pharm Sci. 2018; 4:29-40.

[6] Daraghmeh N, Chowdhry B, Leharne S, Omari M, Badwan A. Coprocessed chitin-mannitol as a new excipient for oro-dispersible tablets. Mar Drugs. 2015; 13:1739-1764.

[7] Daraghmeh N, Rashid I, AI Omari MMH, Leharne SA, Chowdhry BZ, Badwan A. Preparation and characterization of a novel coprocessed excipient of chitin and crystalline mannitol. AAPS PharmSciTech. 2010; 11:1558-1571.

[8] Dong QQ, Zhou MM, Lin X, Shen L, Feng Y. Differences in fundamental and functional properties of HPMC co-processed fillers prepared by fluid-bed coating and spray drying. Eur J Pharm Sci. 2018; 119:147-158.

[9] Edge S, Steele DF, Chen A, Tobyn MJ, Staniforth JN. The mechanical properties of compacts of microcrystalline cellulose and silicified microcrystalline cellulose. Int J Pharm. 2000; 200:67-72.

[10] Fell J, Newton J. Determination of tablet strength by the diametral-compression test. J Pharm Sci. 1970; 59:688-691

[11] Joiris E, Di Martino P, Berneron C, Guyot-Hermann A, Guyot J. Compression behavior of orthorhombic paracetamol. Pharm Res. 1998; 15:1122-1130

[12] Nachaegari SK, Bansal AK. Coprocessed excipients for solid dosage forms. Pharm Technol. 2004; 28:52-64

[13] Nguyen TH, Morton DAV, Hapgood KP. Predicting tablet strength from the wet granulation conditions via the unified compaction curve. Procedia Engineering. 2015; 102:517-526.

[14] Ohwoavworhua FO, Adelakun TA. Non-wood fibre production of microcrystalline cellulose from Sorghum caudatum: characterisation and tableting properties. Indian J Pharm Sci. 2010; 72:295-301

[15] Olayemi O, Oyi A, Allagh T. Comparative evaluation of maize, rice and wheat starch powders as pharmaceutical excipients. Nig J Pharm Sci. 2008; 7:131-138

[16] Osamura T, Takeuchi Y, Onodera R, et al. Formulation design of granules prepared by wet granulation method using a multifunctional single-punch tablet press to avoid tableting failures. Asian J Pharm Sci. 2018; 13:113-119.

[17] Osei-Yeboah F, Feng Y, Sun CC. Evolution of structure and properties of granules containing microcrystalline cellulose and polyvinylpyrrolidone during high-shear wet granulation. J Pharm Sci. 2014; 103:207-215.

[18] Pilpel N. Flow properties of non-cohesive powders. Chem Proc Eng. 1965 46:167

[19] Sonnergaard JM. Quantification of the compactibility of pharmaceutical powders. Eur J Pharm Biopharm. 2006; 63:270277. 
Eur. Pharm. J. 2020, 67(2), 5-14.

Functionality evaluation of co-processed excipients as diluents in tablets manufactured by wet granulation

[20] Sun CC. Microstructure of tablet - pharmaceutical significance, assessment, and engineering. Pharm Res. 2017; 34:918-928.

[21] Sun CC. Decoding powder tabletability: roles of particle adhesion and plasticity. J Adhes Sci Technol. 2011; 25:483-499.

[22] Sun CC. Quantifying effects of moisture content on flow properties of microcrystalline cellulose using a ring shear tester. Powder Technol. 2016; 289:104-108.

[23] United States Pharmacopeial Convention. USP protocol for dissolution studies. In: USP/NF, 2011.

[24] United States Pharmacopoeial Convention. USP protocol for bulk and tapped densities. In: USP/NF, 2012.

[25] Upadhyay P, Khomane KS, Kumar L, Bansal AK. Relationship between crystal structure and mechanical properties of ranitidine hydrochloride polymorphs. CrystEngComm. 2013; 15:3959-3964.

[26] Wang S, Li J, Lin X, et al. Novel coprocessed excipients composed of lactose, HPMC, and PVPP for tableting and its application. Int J Pharm. 2015; 486:370-379.

[27] Yadav JA, Khomane KS, Modi SR, et al. Correlating single crystal structure, nanomechanical, and bulk compaction behavior of febuxostat polymorphs. Mol Pharm. 2017; 14:866-874.

[28] Zeitler J, Rades T. Interdependence of dosage form microstructure and performance. Pharm Res. 2017: 1-3.

[29] Zhang J, Wu C, Pan X, Wu C. On identification of critical material attributes for compression behaviour of pharmaceutical diluent powders. Materials (Basel). 2017; 10:1-16.

[30] British Pharmacopoeia, Volume II. Her Majesty's Stationery Office, London, UK, 2013. 